\title{
KAJIAN ARSITEKTUR TROPIS PADA BANGUNAN RUMAH SAKIT KELUARGA KUDUS ENDE
}

\author{
Petrus Jhon Alfred D.D ${ }^{1}$ \\ ${ }^{1}$ Program Studi Arsitektur, Fakultas Teknik, Universitas Flores, email:ff3redo@gmail.com
}

\begin{abstract}
The Holy Family Hospital is a Maternity Hospital in Ende, Flores, NTT. This hospital is an old building that still survives and resembles a colonial architectural feature that unwittingly adapts to a tropical climate. In tropical climates, heat is a dominant problem most of the time. Tropical climatic conditions require conditions in designing buildings and their environment, this is influenced by specific factors that can only be found specifically in that climate. For this reason, it is necessary to conduct research on the extent to which the Holy Family Hospital building meets the principles of tropical architecture which includes design design elements. In conducting this research, the method used is descriptive qualitative. The descriptive qualitative method is used to describe the design elements of the Holy Family Hospital building design which are closely related to the tropical climate. Data collection was carried out by observation, interviews, and literature literature. The results of the analysis can be concluded that the orientation of the building in the east-west direction is not optimal because it receives heat so that the average room temperature is high. The placement of the building mass results in a more dynamic airflow and airflow movement pattern. Existing ventilation creates breath for air circulation and the room temperature feels cool. The application of lower ventilation reduces humidity on the floor and ground. The canopy is not optimal enough to block out sunlight because its size is not suitable for the angle of incidence of sunlight. The shape of the roof with a slope of 453 and a height of $3-4$ meters is able to drain rainwater properly and help reduce space heating in the building.
\end{abstract}

\section{Keywords: tropical architecture, ende flores, holy family, hospital}

\begin{abstract}
Abstrak
Rumah Sakit Keluarga Kudus adalah Rumah Sakit Bersalin di Ende, Flores, NTT. Rumah Sakit ini merupakan bangunan lama yang masih bertahan dan menyerupai ciri arsitektur kolonial yang tanpa disadari keberadaannya beradaptasi dengan iklim tropis. Di daerah iklim tropis, panas merupakan masalah yang dominan pada hampir sepanjang waktu. Keadaan iklim tropis membutuhkan syarat-syarat dalam merancang bangunan dan lingkungannya, hal tersebut dipengaruhi oleh faktor-faktor spesifik yang hanya dapat dijumpai secara khusus pada iklim tersebut. Untuk itu perlu dilakukan penelitian mengenai sejauh mana bangunan Rumah Sakit Keluarga Kudus ini memenuhi prinsip-prinsip arsitektur tropis yang meliputi elemen desain rancangannya. Dalam melakukan penelitian ini metode yang digunakan adalah kualitatif deskriptif. Metode kualitatif deskriptif digunakan untuk menguraikan elemen desain rancangan bangunan Rumah Sakit Keluarga Kudus yang berkaitan erat dengan iklim tropis. Pengumpulan data dilakukan dengan observasi, wawancara, dan literatur kepustakaan. Hasil Analisa dapat disimpulkan bahwa orientasi bangunan arah timur-barat belum optimal karena menerima panas sehingga suhu ruangan rata-rata tinggi. Penempatan massa bangunan menghasilkan aliran udara dan pola pergerakan aliran udara lebih dinamis. Ventilasi yang ada menciptakan nafas untuk sirkulasi udara dan suhu ruangan terasa sejuk. Penerapan ventilasi bawah mengurangi kelembaban pada permukaan lantai dan tanah. Kanopi belum optimal menghalau sinar matahari karena ukurannya kurang sesuai dengan sudut datang sinar matahari. Bentuk atap dengan kemiringan $45^{\circ}$ dan tinggi $3-4$ meter mampu mengalirkan air hujan dengan baik dan membantu mengurangi pemanasan ruang di dalam bangunan.
\end{abstract}

Kata-kunci: arsitektur tropis, ende flores, keluarga kudus, rumah sakit

\section{Pendahuluan}

Iklim merupakan hal terpenting yang berpengaruh secara langsung terhadap kenyamanan suatu tempat tinggal. Iklim dipengaruhi oleh beberapa faktor seperti, panas yang dihasilkan dari paparan sinar matahari, kelembaban udara yang disebabkan curah hujan tinggi dan pengaruh pergerakan udara (Aprita, 2020). Menurut Lippsmeier dalam Sarjono (2011) Indonesia masuk dalam kategori daerah hujan tropis atau tropika basah yang berada di daerah katulistiwa yaitu $15^{\circ}$ selatan dan utara. Dimana karakter 
iklim tropis ditandai dengan ciri-ciri yang disampaikan oleh Lippsmeier (1994) adalah kelembaban tinggi, curah hujan tinggi (sekitar $2000-5000 \mathrm{~mm}$ ), rata-rata suhu $23^{\circ} \mathrm{C}$ sampai dengan $38^{\circ} \mathrm{C}$ pada musim panas, radiasi matahari tinggi yakni berkisar $1500-2500 \mathrm{kwh} / \mathrm{m} 2 /$ tahun.

Di iklim tropis lembab terdapat dua musim dalam tiap tahunnya, yakni musim kemarau yang berlangsung antara bulan Maret sampai Agustus dan musim penghujan yang berlangsung antara bulan September sampai Pebruari, seperti yang disampaikan oleh Szokolay (1980). Menurut Purwanto (2006), prinsip yang ditekankan dalam arsitektur tropis adalah bangunan yang dapat menahan pengaruh negatif dari iklim tropis agar tidak masuk ke dalam bangunan. Jadi bentuk bangunan bisa fleksibel. Hal ini sejalan dengan apa yang disampaikan oleh Karyono (2010) untuk menjawab seluruh persoalan iklim tropis bentuk rancangan harus tanpa batas.

Selanjutnya Lipsmeier (1994) mengatakan bahwa bangunan di iklim tropis memiliki ciri utama: 1) keterbukaan (openness) untuk mengalirkan udara dan mengurangi kelembaban dalam bangunan. 2) bayangan (shading) untuk melindungi bagian dinding dan lantai dari panas serta silau sinar matahari. (3) bangunan memiliki lantai yang berpanggung untuk mengatasi kelembaban dari tanah. Ciri bangunan yang diuraikan tersebut diatas masih banyak dijumpai pada bangunan-bangunan lama di Kabupaten Ende, khususnya di kota Ende. Bangunan-bangunan lama tersebut masih bertahan dan menyerupai ciri arsitektur kolonial, seperti Rumah Sakit Keluarga Kudus Ende.

Rumah Sakit Keluarga Kudus beralamat di jalan Mesjid Kelurahan Rukun Lima Kecamatan Ende Selatan, Kabupaten Ende, Flores, NTT. Bangunan ini adalah bangunan lama yang menyerupai ciri arsitektur kolonial yang tanpa disadari keberadaannya menyusaikan dengan kondisi iklim tropis. Saat ini bangunan telah mengalami perubahan karena faktor umur bangunan, beberapa bagian terlihat rusak dan terjadi perubahan bentuk karena adanya renovasi. Oleh karena itu dilakukan penelitian mengenai sejauh mana bangunan Rumah Sakit Bersalin Keluarga Kudus ini memenuhi prinsip-prinsip arsitektur tropis yang meliputi elemen desain rancangannya.

\section{Tinjauan Pustaka}

\section{Rumah Sakit Keluarga Kudus Ende}

Rumah Sakit Keluarga Kudus awalnya diberi nama Rumah Bersalin Sarvae Spiritus Sanctus (SSpS). Rumah Bersalin ini didirikan pada 1 Nopember 1960 oleh Suster Guntir dari Jerman. Pada tanggal 21 Pebruari dilakukan peletakan batu pertama dan sekaligus Peresmian BKIA (Balai Kesejahteraan Ibu dan Anak) pada tahun 1960. Lembaga ini berkerjasama dengan SPK Lela dan SPK Ende. Pemiliknya oleh Suster SSpS, pada tanggal 1 April 2015 hingga kini status rumah bersalin menjadi Rumah Sakit Keluarga Kudus.

Pelayanan yang diberikan pada Rumah Sakit ini adalah perawatan ibu hamil, persalinan, nivas, dan bayi. Tenaga yang bekerja saat ini berjumlah 20 orang yaitu bidan, perawat, analis, rekan medis, keuangan, dan administrasi. Rumah Sakit ini memiliki 2 orang dokter umum, hingga kini pemiliknya oleh Suster SSpS (Provinsi SSpS Flores Bagian Timur yang bernaung dibawah Yayasan Stenmanns yang berkedudukan di Kewapante-Maumere).

Rumah Sakit Keluarga Kudus Ende, memiliki tiga buah massa bangunan. Massa bangunan pertama adalah bangunan utama dipergunakan untuk rumah sakit. Bangunan lainnya ditempatkan pada bagian belakang dari bangunan utama, yang difungsikan untuk ruang kerja para suster SSpS dan karyawan, ruang tidur suster SSpS dan karyawan, ruang peralatan, gudang, dapur, dan ruang-ruang lainnya. Di bangunan utama, di bagian depan rumah sakit ini terdapat ruang tunggu dan ruang loket. Bagian dalam terdapat ruang bersalin yang difungsikan sebagai ruang khusus untuk persalinan yang dibuka selama 24 jam. Dan ada juga Ruang Nivas, ruang Nivas adalah ruang untuk pasien bersalin setelah seorang pasien/ibu melahirkan bayi, yang dipergunakan untuk memulihkan kesehatannya. Ruang Administrasi diletakan berdekatan dengan ruang loket. Ada juga Ruang Medis, yang difungsikan untuk ruang penyimpanan peralatan medis dan Ruang Bayi, untuk penyimpanan bayi.

\section{Arsitektur Tropis}

Di daerah iklim tropis, panas merupakan masalah yang dominan pada hampir setiap waktu terjadi dengan suhu rata-rata per tahunnya diatas $20^{\circ} \mathrm{C}$ (Koenigsberger. dkk, 1975). Santosa (1997), iklim tropis ditandai dengan adanya perbedaan suhu antara siang dan malam, kelembaban udara cukup tinggi yang terjadi saat malam hari serta cukup rendah pada siang harinya, dengan rata-rata kecepatan angin di siang hari cukup memadai untuk mendapatkan kenyamanan yaitu $1.0 \mathrm{~m} /$ detik pada musim hujan dan sekitar $2.0 \mathrm{~m} /$ detik pada musim panas.

Keadaan iklim tropis membutuhkan syarat-syarat dalam merancang bangunan dan lingkungannya, hal tersebut dipengaruhi oleh faktor-faktor spesifik yang hanya dapat dijumpai secara khusus pada iklim tropis. Ada beberapa prinsip dalam desain bangunan di iklim tropis menurut beberapa ahli dan peneliti seperti; Fanger (1970) menyatakan bahwa besaran dan pola aliran udara dalam ruangan tidak hanya 
tergantung dari kecepatan udara luar tetapi juga di tentukan oleh elemen-elemen desain arsitektur lainnya yaitu orientasi dan peletakan bangunan, bentuk atap, balkon, desain jendela, susunan ruang didalam, penempatan perabotan dan bentuk desain partisinya.

Menurut Lippsmeir (1994); a). denah pada arsitektur tropis berbentuk persegi panjang, orientasinya terhadap matahari lebih menguntungkan dibandingkan dengan bujur sangkar. b). di daerah tropika-basah lubang pada dinding pada sisi sebelah atas dan bawah, angin sebisa mungkin berukuran besar. c). untuk mendapatkan ventilasi silang lubang - lubang harus dibuat pada sisi-sisi bangunan yang berlawanan. Dan menurut Givoni (1998) di daerah equator, pada bagian sisi timur - barat mendapatkan panas yang lebih tinggi dibandingkan pada sisi utara - selatan. Di siang hari pada umumnya tempertur udara dalam bangunan lebih rendah daripada temperature udara luar bangunan, sedangkan pada malam hari tempertur udara dalam bangunan lebih tinggi dari tempertur udara luar.

Selanjutnya menurut Karyono (1998); a). untuk bangunan dengan atap miring perlu dipertimbangkan untuk bisa menghindari terjadinya panas pada ruang antara penutup atap dan langitlangit. Oleh karena itu, ruang-ruang tersebut diberi bukaan, untuk memudahkan aliran udara silang menghapus panas yang terakumulasi. b). apabila pada bagian sisi timur dan barat bangunan tidak dapat dihindari untuk menempatkan ruang-ruang utama, maka untuk menghindari terjadinya panas pada ruang tersebut dinding-dinding ruangannya harus diberi penghalang terhadap sinar matahari langsung. c). Banyaknya vegetasi serta tiupan angin yang optimal mampu menghasilkan kenyamanan pengguna bangunan.

Hasil penelitian Santosa (2001) pada ketiga bangunan yaitu hunian tradisional, hunian kolonial dan hunian modern didapatkan bahwa; a). bangunan dengan ruang geometri yang kompak dan sederhana dalam bentuk single zone merupakan bentuk yang potensial untuk dapat menghalau panas, sehingga temperature udara didalam ruang menjadi lebih rendah dari tempetarur luar. b). fungsi konstruksi berat (dinding dan atap) pada studi kasus menghasilkan penurunan temperature udara dalam ruang yang sangat siknifikan, baik di waktu siang maupun malam hari. c). dengan luasan bukaan 40\%, perbedaan temperature udara didalam hunian kolonial menjadi siknifikan. Karena luasan bidang masip menjadi berkurang, maka jumlah panas yang ditangguhkan menjadi lebih sedikit. Pendapat ini diperkuat dengan hasil penilitian dari Samodra (2009) yaitu, kondisi ruangan yang baik apabila terdapat bukaan lebih luas antar ruang dalam bangunan. Tujuannya untuk memberikan pertukaran udara yang cukup dari lingkungan ke bangunan secara merata. Dengan demikian dapat meningkatkan nilai pertukaran udara bangunan.

Rosadi (2012), menyatakan bahwa semakin besar sudut kemiringan atap maka semakin dingin suhu yang dihasilkan dalam ruangan karena dipengaruhi besaran ruangan sudut sehingga penyerapan panas cukup maksimal. Kemampuan atap menahan panas ini juga dibuktikan oleh peneliti lain dan menemukan bahwa atap merupakan elemen bangunan yang sangat penting dalam proses pembentukan passive cooling didaerah tropis lembab (Malama, 1996).

Dari teori-teori dan hasil penelitian dari beberapa ahli dan peneliti diatas dapat dijadikan rujukan untuk melakukan analisis terhadap penerapan prinsip-prinsip arsitektur tropis pada elemen desain rancangan bangunan Rumah Sakit Keluarga Kudus Ende.

\section{Metode \\ Jenis Data}

Data-data dalam penelitian ini diambil berdasarkan variabel-variabel yang telah ditetapkan. Data tersebut secara umum diklasifikasikan menjadi dua jenis yaitu:

\section{a. Data primer}

Data primer berupa data yang didapatkan dari hasil studi lapangan yaitu: observasi, pengukuran, fotografi dan wawancara. Data primer meliputi: data lokasi, orientasi bangunan, dan data bangunan.

\section{b. Data sekunder}

Data sekundar adalah data yang berupa literatur ataupun data kepustakaan berupa buku-buku, jurnal, artikel, ataupun hasil penelitian terdahulu yang berkaitan dengan permasalahan penelitian. Data ini digunakan untuk menelaah referensi-referensi yang berhubungan, sehingga data ini dapat bermanfaat untuk menguji dan menganalisis dan juga memprediksikan hasil atau jawaban dari permasalahan penelitian.

\section{Teknik Pengumpulan Data}

Pengumpulan data yang dilakukan yaitu dengan terlibat langsung ke lapangan dengan melakukan pengamatan, wawancara kepada nara sumber, mengumpulkan dokumen-dokumen di lapangan dengan menggunakan alat-alat, misalnya alat perekam suara (recorder), kamera, dan juga alat tulis.

\section{Analisa Data}

Dalam melakukan penelitian ini metode yang digunakan yaitu kualitatif deskriptif. Metode kualitatif deskriptif digunakan untuk menguraikan elemen desain rancangan bangunan Rumah Sakit Keluarga 
Kudus Ende yang berhubungan dengan iklim tropis. Tujuan dari kajian deskriptif ini untuk mendeskripsi, gambaran atau lukisan secara sistematis, faktual dan akurat mengenai fakta-fakta, sifat-sifat serta hubungan antar fenomena yang diselidiki (Groat \& Wang, 2002). Hasil dari observasi, wawancara dan studi kepustakaan digunakan untuk menguji dan menganalisis, seberapa jauh bangunan Rumah Sakit ini menerapkan dan memenuhi prinsip-prinsip arsitektur tropis.

\section{Hasil dan Pembahasan}

\section{Penerapan Prinsip Arsitektur Tropis}

\section{Orientasi Bangunan}

Orientasi dari fasad depan bangunan rumah sakit ini menghadap ke sisi timur - barat, dimana pada bagian timur dan barat menerima sinar matahari secara langsung pada pagi dan sore hari. Pada bagian barat dan timur mendapatkan panas yang cukup tinggi karena dinding terpanjang berada pada sisi ini. Sedangkan pada sisi utara dan selatan adalah sisi terpendek. Penempatan orientasi bangunan tersebut kurang tepat, karena letaknya langsung berhadapan dengan matahari, sehingga kondisi suhu ruangan pada sisi dinding timur - barat rata-rata lebih tinggi dibanding kondisi suhu ruang pada sisi utara selatan. Namun kondisi ini diatasi dengan dibuatnya ruangan yang tinggi, mencapai 3-4 kali tinggi manusia dan memiliki lubang angin dengan jumlah relative banyak sehingga membuat ruangan-ruangan pada bangunan tersebut tidak panas, dan cenderung sejuk.

Ketebalan dinding bangunan ini adalah satu batu bata $(30 \mathrm{~cm})$ dinding dengan ketebalan $30 \mathrm{~cm}$ mampu memberikan kesejukan udara dalam ruangan tetap terjaga. Ketebalan dinding adalah salah satu cara untuk mereduksi udara yang panas dalam ruangan. Hembusan angin pada bangunan ini masih kurang karena orientasi bangunan yang berada pada sisi timur. Arah sumber angin datangnya dari sisi barat laut, jadi angin yang masuk lebih banyak melalui pintu, jendela, ventilasi dari arah belakang (sisi bagian barat) dari bangunan rumah sakit.

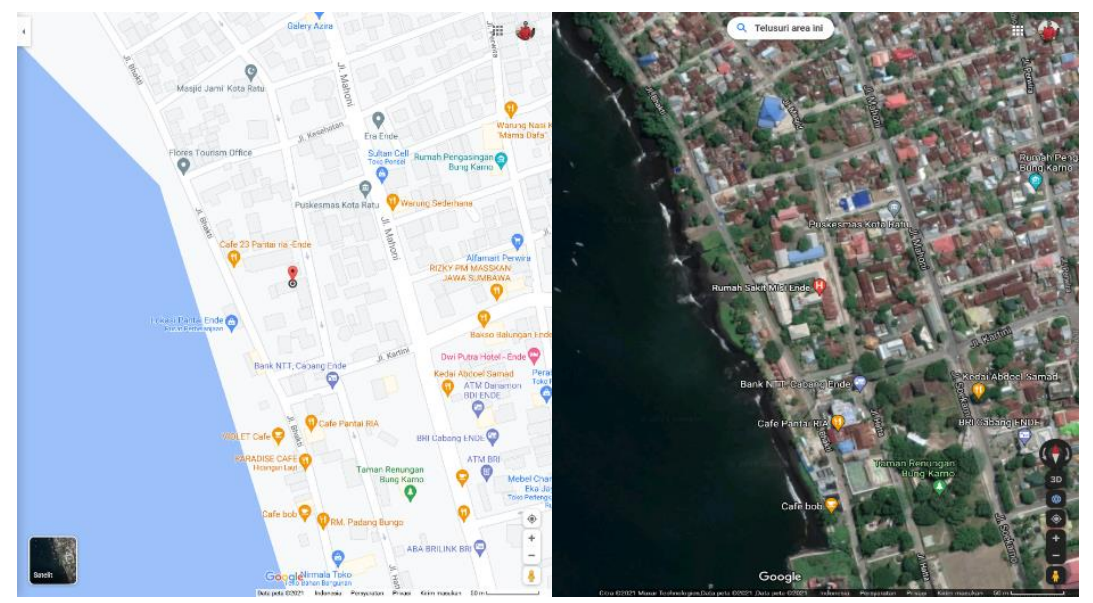

Gambar 1. Peta Lokasi Rumah Sakit Keluarga Kudus Ende Sumber: Google Map dan Google Eart

\section{Penghawaan (Ventilasi)}

Penempatan massa bangunan pada rumah sakit ini diletakan secara berjauhan/ terpisah, cara ini membantu memperbesar terjadinya aliran udara masuk kedalam bangunan. Jendela (lubang angin/ ventilasi tengah) juga memegang peran penting dalam suatu bangunan karena berpengaruh terhadap cahaya alami dan pertukaran udara dari luar dan dari dalam ke luar. Di lingkungan sekitar dan dalam bangunan rumah sakit ini, angin sudah terasa sejuk dan nyaman. Karena tipe bukaan jendela yang digunakan merupakan jendela yang memiliki banyak lubang sehingga membuat angin dapat masuk ke dalam bangunan. Letak pintu dan jendela saling berhadapan, hal ini memungkinkan adanya ventilasi silang (cross ventilation), dimana udara dalam ruang dapat bergerak secara alami dan mudah keluar masuk ruangan dengan lancar. 


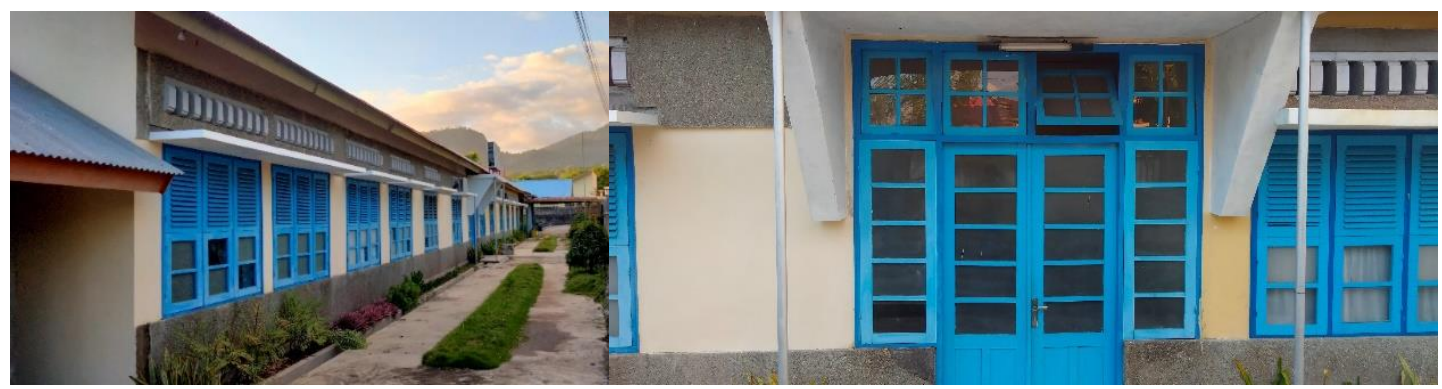

Gambar 2. Tampak Depan Rumah Sakit Keluarga Kudus Ende Sumber: Dokumen Pribadi, 2021

Desain jendala pada sisi barat dan timur berupa jalusi. Jendela jalusi berfungsi untuk menahan sinar matahari tetapi masih dimungkinkan udara dari luar tetap dapat masuk ke dalam ruang. Pada sisi bagian timur dan utara terdapat bukaan-bukaan yang banyak, ini memungkinkan untuk memberikan aliran udaradi sekitar lingkungan dapat masuk ke bangunan secara merata.

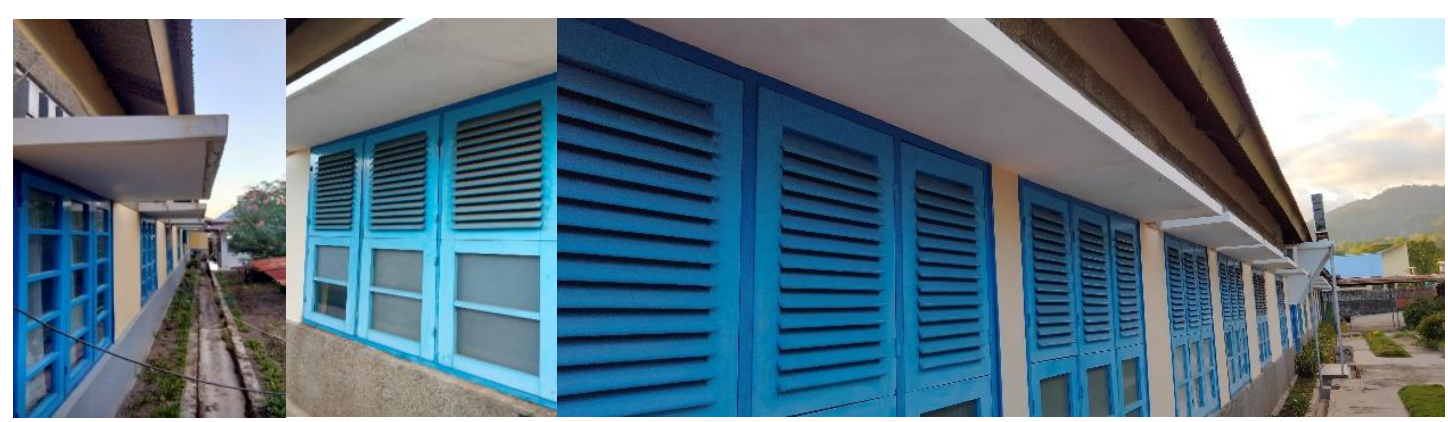

Gambar 3. Jendela ukuran $100 \times 60 \mathrm{~cm}$, pada sisi barat dan timur sebanyak 120 buah Sumber: Dokumen Pribadi, 2021
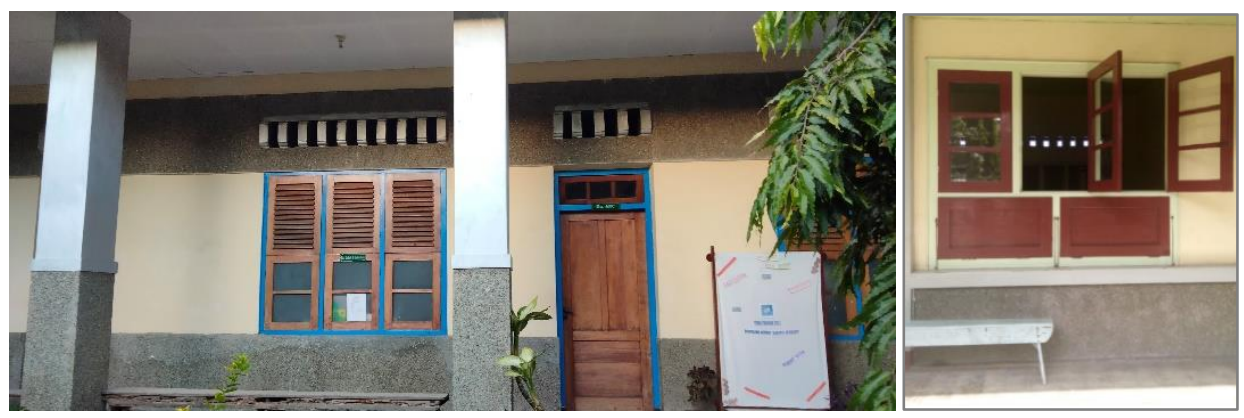

Gambar 4. Jendela ukuran $100 \times 60 \mathrm{~cm}$ dan $60 \times 40$, arah barat sebanyak 20 buah dan selatan sebanyak 12 buah. Sumber: Dokumen Pribadi, 2021

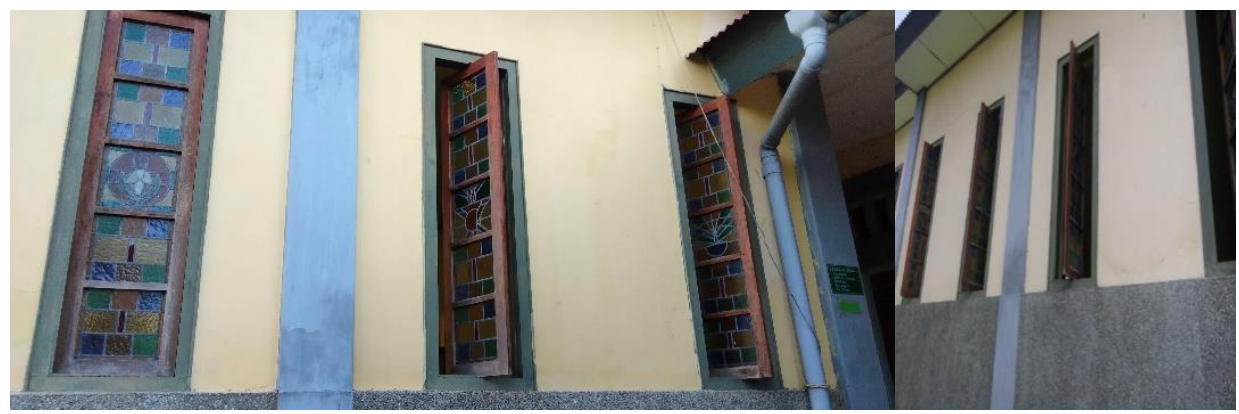

Gambar 5. Jendela ukuran 120x60, arah selatan sebanyak 12 buah. Sumber: Dokumen Pribadi, 2021

Ventilasi Atas (lubang angin atas) pada bangunan ini mempunyai ukuran yang relatif tidak besar yaitu $15 \times 15 \mathrm{~cm}$, jumlahnya cukup banyak dan diletakan disetiap sisi (timur, barat, utara dan selatan) 
ada juga yang berukuran besar yaitu 35x35 diletakan di sisi timur (bagian depan bangunan), tepatnya diletakan diatas pintu masuk. Dengan demikian proses terjadinya pertukaran udara dari luar ke dalam dan dari dalam ke luar cukup baik. Di bangunan Rumah Sakit ini juga terdapat ventilasi atap (lubang angin pada atap). Ventilasi atap berada pada bagian belakang bangunan. Ventilasi atap diletakan antara atap dan langit-langit dengan jumlah relative banyak. Tujuan dari ventilasi atap ini agar udara yang panas di bawahpenutup atap mudah dialirkan keluar agar panas tidak merambat keatas langit-langit, hal ini sangat membantu untuk pencapaian suhu ruang yang rendah dan memberikan kesejukan di dalam ruangan.

Ventilasi atap dapat juga berfungsi untuk mengeluarkan udara panas yang terperangkap di bawah penutup atap (karena radiasi matahari) sehingga mudah dibuang dan mengalir keluar, agar panas tersebut tidak merambat ke langit-langit. Ruangan yang memiliki ventilasi atap adalah ruangan karyawan, dapur dan gudang dimana ruangan ini digunakan untuk tempat kerja dan tidur karyawan, ruang penyimpanan peralatan dan makanan. Ruangan ini memilki jendela untuk sirkulasi udara dibawah atap, sehingga terkesan terlihat dari arah luar seperti bangunan bertingkat. Di bagian belakang terdapat cerobong asap. Cerobong asap diletakan diatas atap bangunan, tepatnya di bawah ruangan dapur. Fungsi cerobong asap ini agar sirkulasi udara kotor dari dapur (asap) dapat keluar dengan mudah dan terjadi pertukaran udara dari luar sangat baik sehingga asap yang dihasilkan di dapur tidak dapat masuk ke ruangan lain yang berada di sekitarnya.
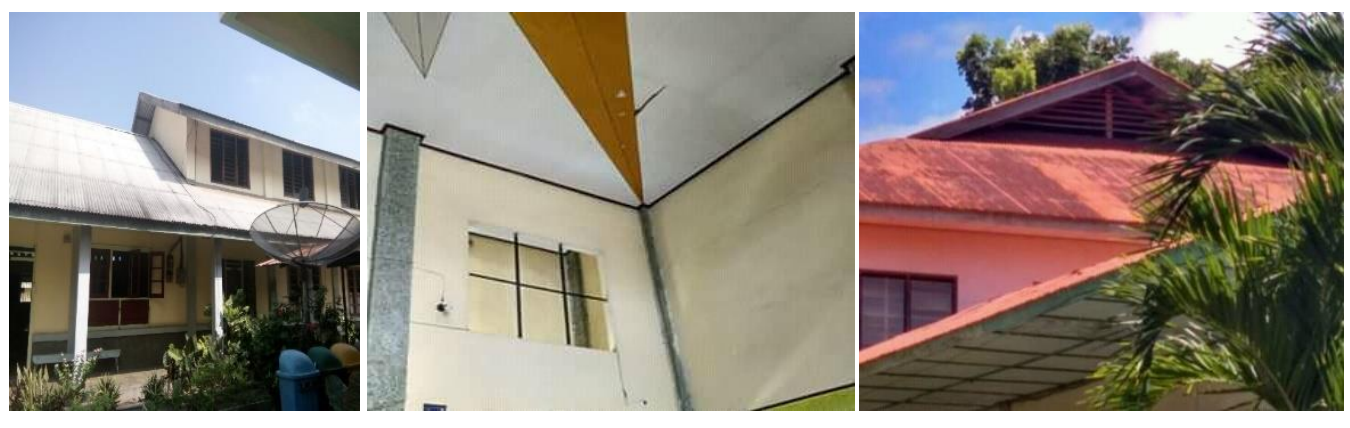

Gambar 6. Ventilasi atas barat dan timur ukuran $150 \times 200 \mathrm{~cm}$ dan $50 \times 50 \mathrm{~cm}$ Sumber: Dokumen Pribadi, 2021

Jendela (ventilasi tengah) diletakkan pada arah timur, barat, selatan, dan utara. Jendela berukuran 100x60 cm, diletakkan menghadap kearah barat dan timur sebanyak 120 buah. Jendela tersebut menggunakan kayu dengan model jendela ganda (krepyak) berjenis jalusi dari kayu dan kaca polos. Pada arah barat dan selatan, jendela berukuran $100 \times 60 \mathrm{~cm}$ dan $60 \times 40$, sebanyak 20 buah dan sebanyak 12 buah, berukuran $120 \times 60 \mathrm{~cm}$ sebanyak 12 buah diletakkan menghadap kearah selatan. Kedua jendela ini menggunakan model jendela ganda berbahan kaca polos.

Ventilasi atas diletakkan menghadap kearah timur, barat, selatan, dan utara. Kearah salatan dan utara sebanyak 20 buah, dengan ukuran $15 \times 30 \mathrm{~cm}$. Tipe dari jalusi/ krepyak, jendela jalusi/ krepyak salah satu alternatif agar udara seqar selalu masuk kedalam ruangan selama 24 jam. Dan ventilasi bawah diletakkan menghadap kearah utara sebanyak 16 buah, tipe ventilasi boven dengan ukuran $30 \times 30 \mathrm{~cm}$. Serta terdapat ventilasi atap pada bangunan ini yang diletakkan pada arah barat dan timur dengan ukuran $150 \times 200 \mathrm{~cm}$.

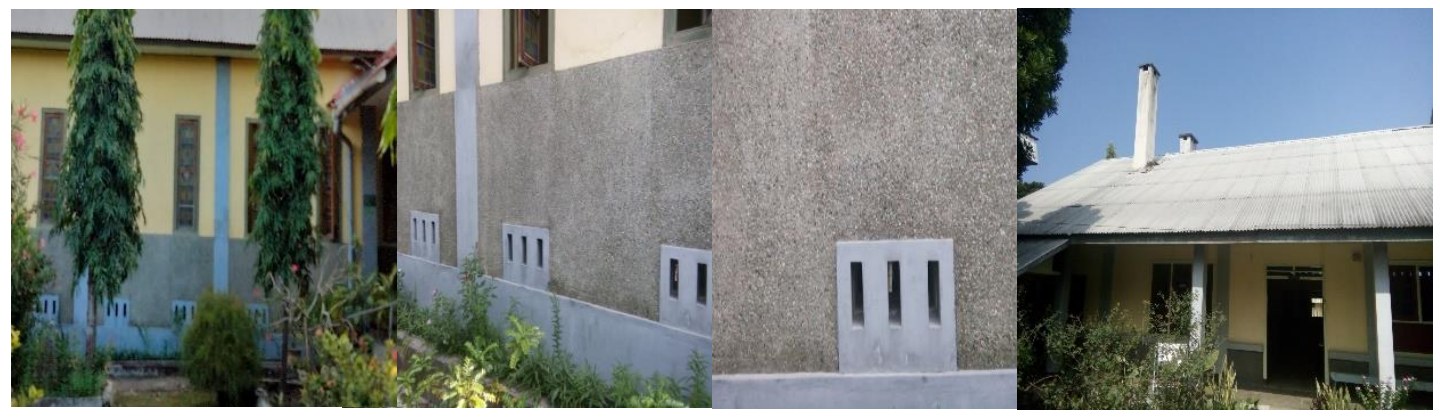

Gambar 7. Ventilasi bawah, arah selatan ukuran $30 \times 15 \mathrm{~cm}$, sebanyak 12 buah dan 2 buah cerobong asap. Sumber: Dokumen Pribadi, 2021

\section{Pelindung Dari Radiasi Sinar Matahari}

Pelindung dari radiasi sinar matahari langsung bisa diaplikasikan melalui beberapa alternative diantaranya; menggunakan double façade, sun shading, peletakan vegetasi (Arisal, 2020) atau 
penggunaan kanopi. Fungsi utama kanopi adalah melindungi penghuni maupun bagian luar suatu bangunan dari sinar matahari ataupun terpaan hujan, namun selain fungsi tersebut kanopi juga mempunyai fungsi yag tidak kalah pentingnya, diantaranya kanopi mampu memberikan nilai dekoratif pada bangunan. Kanopi pada bangunan rumah sakit ini diletakan dibagian atas pintu atau jendela (antara ventilasi atas dan tengah). Ukuran kanopi 50x100 centimeter terbuat dari beton, sebanyak 8 buah dan ditempatkan dibagian atas jendela sedangkan dibagian atas pintu berjumlah 1 buah dengan ukuran $100 \times 150$ centimeter.

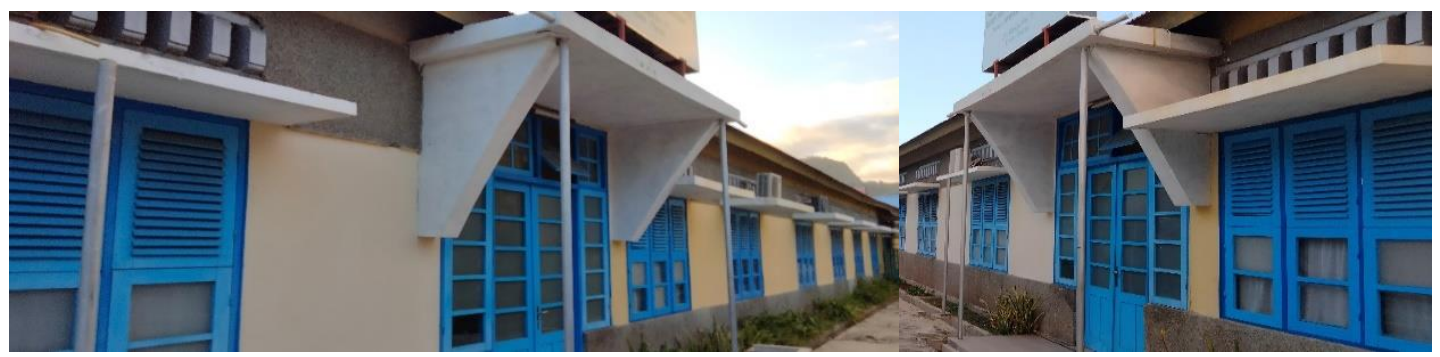

Gambar 8. Kanopi pada bagian atas pintu dan jendela pada bagian utara dan timur.

Sumber: Dokumen Pribadi, 2021

\section{Pelindung Dari Curah Hujan}

Bangunan dominan menggunakan konstruksi atap yang bersudut $45^{\circ}$. Hal ini terlihat pada bentuk atap bangunan utama maupun pada bangunan lainnya. Atap dibuat cukup lebar dan tinggi yang mencapai 3 - 4 meter, sehingga mampu mencegah air hujan untuk masuk kedalam bangunan. Atap yang tinggi dan lebar dapat mengalirkan air hujan dengan mudah kebawah sehingga dapat terhindar dari genangan air pada atap atau kanopi yang berbentuk datar. Selain itu, atap yang tinggi memiliki volume ruang antara penutup atap dan langit-langit cukup besar, ini dapat membantu mengurangi pemanasan ruang-ruang dalam bangunan sehingga ruangan semakin dingin.

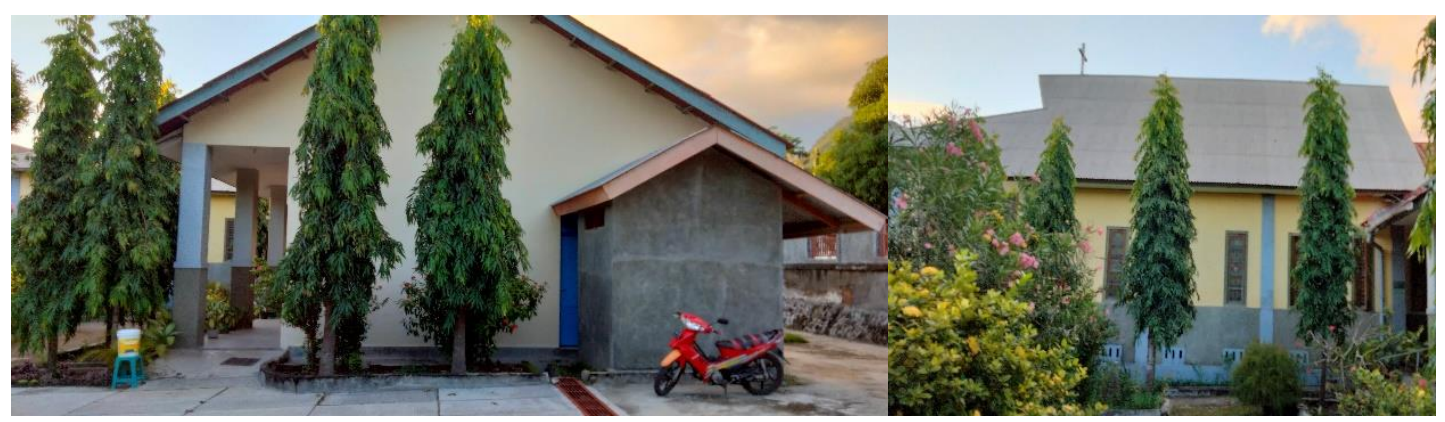

Gambar 9. Konstruksi atap yang bersudut $45^{\circ}$ dengan tinggi 3 - 4 meter. Sumber: Dokumen Pribadi, 2021

\section{Kesimpulan}

Dari hasil pembahasan diatas dapat disimpulkan bahwa orientasi bangunan, penghawaan, pelindung radiasi matahari, dan pelindung dari hujan dapat mempengaruhi aspek tropikalitas. Orientasi bangunan arah Timur-Barat memaksimalkan siklus orientasi matahari secara optimal untuk penerangan namun menimbulkan panas sehingga suhu ruangan pada sisi dinding barat dan timur rata-rata lebih tinggi. Penempatan massa bangunan menghasilkan sirkulasi udara dan pola pergerakan aliran udara lebih dinamis sehingga menghapus udara panas dilingkungan dan didalam bangunan. Ventilasi yang ada menciptakan nafas untuk sirkulasi udara sehingga menjadikan suhu ruangan terasa sejuk. Penerapan ventilasi bawah membantu menghapus udara dan mengurangi kelembaban pada permukaan lantai dan tanah. Kanopi sebagai pelindung dari sinar matahari ataupun terpaan hujan, masih belum optimal menghalau panas matahari dengan baik disebabkan ukurannya tidak mempertimbangkan dengan sudut kemiringan sinar matahari. Bentuk atap dengan kemiringan $45^{\circ}$ dengan tinggi $3-4$ meter mampu mengalirkan dan mencegah air hujan dengan baik serta membantu mengurangi pemanasan ruang dalam bangunan. 
Jurnal Arsitektur AIDR - Vol 4 No 2 September 2021

e-ISSN 2685-1490; p-ISSN 2615-1472

\section{Daftar Pustaka}

Aprita, D. R. (2020). Arsitektur Tropis Pada Tata Ruang Dan Permukiman Di Kampung Pulo Garut. Jurnal Arsitektur ZONASI, 3(3), 413-421.

Arisal, Y. S. (2020). Analisis Penerapan Arsitektur Tropis Pada Bangunan Kantor Sewa Wisma Dharmala Sakti jakarta. Purwa Rupa,, 4(1), 53-58.

Fanger, P. (1970). Thermal Comfort: Analysis And Applications In Environmental Engineering. New York: McGrawHill.

Givoni, B. (1998). Climate Considerations In Building and Urban Design. New York: Van Nostrand Reinhold.

Groat, L. a. (2002). Architectural Research Methods. Canada: Jhon Wiley \& Sons.

Karyono, T. H. (1998). Arsitektur Tropis dan Bangunan Hemat Energi. Jurnal KALANG, Jurusan Teknik Arsitektur, Universitas Tarumanagara, 1(1).

Karyono, T. H. (2010). Arsitektur dan Kota Tropis Dunia Ketiga: Suatu Bahasan tentang Indonesia. Depok: PT Raja Grafindo.

Koenigsberger, O. e. (1975). Manual Of Tropical Housing and Building Part 1: Climatic Design. London: Longman.

Lippsmeier, G. (1994). Bangunan Tropis. Jakarta: Erlangga.

Malama, A. d. (1996). Thermal and Economic Implications of Passive Cooling Strategies in Low-Cost Housing in Tropical Upland Climate. Architectural Science Review, 39(2), 95-106.

Purwanto, L. (2006). Arsitektur Tropis dalam Penerapan Desain Arsitektur. Semarang: Unika Soegija Pranata.

Rosadi, H. N. (2012). Pengaruh Sudut Kemiringan Atap Bangunan dan Orientasinya Terhadap Kualitas Termal. Prosiding Temu IImiah IPLBI, 93-96.

Samodra, F. B. (2009). Spesifikasi Kinerja Termal Sistim Konstruksi Kulit Rumah Tinggal Tropis dalam Variasi Altitude. Surabaya: Seminar Nasional Pascasarjana IX - ITS.

Santosa, M. (1997). Arsitektur Tradisional Tropis Lembab: Sebuah Referensi untuk Pengembangan Arsitektur di Indonesia. Surabaya: Kumpulan Karya Ilmiah, Jurusan Arsitektur ITS.

Santosa, M. (2001). Harmoni di Lingkungan Tropis Lembab: Keberhasilan Bangunan Kolonial. Dimensi Teknik Arsitektur, 29(1), $34-42$.

Sardjono, A. B. (2011). Respon Rumah Tradisional Kudus Terhadap Iklim Tropis. Modul, 11(1), 7-16.

Szokolay, S. (1980). Environmental Scince Handbook For Architecs And Builders. Lancaster: The Construction Press. 